\title{
An evaluation of the reliability of the neutrophil-to- lymphocyte ratio in patients with acute cholecystitis undergoing laparoscopic surgery
}

\author{
Yaşar Özdenkaya, $\bullet$ Refik Bademci
}

Department of General Surgery, İstanbul Medipol University Faculty of Medicine, İstanbul, Turkey

\begin{abstract}
Introduction: Acute cholecystitis is observed quite commonly in emergency surgery clinics and parameters are needed for diagnosis and treatment. The aim of this study was to determine whether the neutrophil-tolymphocyte ratio (NLR) is of benefit in the diagnosis of acute cholecystitis.

Materials and Methods: A retrospective evaluation of patients who were hospitalized between January 2014 and February 2018 for the treatment of acute cholecystitis was conducted. The blood tests and radiological tests of the patients were evaluated. The NLR was calculated and compared with the clinical and laboratory values of the patients.

Results: A total of 185 patients were identified, comprising 102 (55.1\%) females and 83 (44.9\%) males with a mean age of $51.5 \pm 15.9$ years. The mean leukocyte count was $11.6 \pm 3.610 \% / \mathrm{L}$ and the mean C-reactive protein (CRP) value was $37 \pm 76.4 \mathrm{mg} / \mathrm{L}$. Overall, 90 (48.6\%) patients had normal leukocyte values and 59 (31.8\%) patients had normal CRP values. In 20 (10.8\%) patients with an NLR of approximately 1, only 1 (5\%) was aged $>60$ years and all of the remaining patients were $<45$ years of age. In $53(28.6 \%)$ patients, the NLR was determined to be approximately 2 , and the NLR value was $\geq 3$ in 112 (60.5\%) patients.

Conclusion: Awareness of an increased NLR may be beneficial in the diagnosis of patients with acute cholecystitis.
\end{abstract}

Keywords: Acute cholecystitis; C-reactive protein; laparoscopy; neutrophil-to-lymphocyte ratio.

\section{Introduction}

\section{Acute Cholecystitis}

Significantly high numbers of patients are admitted to emergency surgery clinics with a diagnosis of acute cholecystitis. Acute cholecystitis is a disease characterized by inflammation and the progression of acute cholecystitis may vary widely. ${ }^{[1]}$ Although self-limiting in some patients, in others it can progress to gangrenous cholecystitis. Many diagnostic methods are used in the diagnosis of acute cholecystitis such as the Murphy sign, ultrasonography (USG) and computed tomography (CT). ${ }^{[2]}$ The Tokyo criteria are generally used for the diagnosis of acute cholecystitis, ${ }^{[3]}$ but there is still a need for new parameters to ac- 
curately determine the progression of acute cholecystitis. The neutrophil-to-lymphocyte ratio (NLR) is important for detecting the degree of inflammation and progression of the disease in many inflammatory illnesses. ${ }^{[4]}$

The aim of this study was to determine whether NLR is of benefit in the diagnosis of acute cholecystitis.

\section{Materials and Methods}

A retrospective examination was made of 2060 patients who underwent cholecystectomy, and from these, the study included patients who presented for emergency surgery with a diagnosis of acute cholecystitis. The diagnosis of acute cholecystitis was made from the anamnesis, physical examination hemogram, CRP, USG findings and if necessary, computed tomography (CT) and magnetic resonance imaging (MRI) findings.

Physical examination and imaging findings of the patients were recorded. The results of diagnostic tests conducted during admission to the emergency clinic were recorded for the purposes of this study. It was noted whether or not endoscopic retrograde cholangio-pancreatography (ERCP) was performed on the patient.

Hemogram, white blood cell count, C-reactive protein (CRP), aspartate aminotransferase (AST), and alanine transaminase (ALT) tests were conducted after admission and the results were recorded. Age, gender and operative characteristics of the patients were determined. Leukocyte, lymphocyte and neutrophil values were determined from the hemogram, and the NLR was calculated.

The elevated rates of the NLR, CRP and leukocyte values of patients operated on because of acute cholecystitis in general and over 50 years of age were evaluated and accordingly the efficacy of NLR in the diagnosis was evaluated.

Statistical analysis was performed using SPSS vn 25.0. software (SPSS for Windows; SPSS Inc., Chicago, IL, USA). Descriptive analyses were summarized in terms of frequency and percentage. Data were expressed as mean \pm standard deviation and percentage values. A value of $\mathrm{p}<0.05$ was accepted as statistically significant.

\section{Results}

A total of 185 patients were identified, comprising 102 (55.1\%) females and 83 (44.9\%) males with a mean age of $51.5 \pm 15.9$ years; 97 patients were aged $>50$ years. The AST
Table 1. Clinical and laboratory features of patients operated on for acute cholecystitis

Total: 185

\begin{tabular}{lc} 
Age (years)* & $51.5(15.9)$ \\
Female, $\mathrm{n}(\%)$ & $93(50.2)$ \\
Leukocyte $\left(10^{9} / \mathrm{L}\right) *$ & $9.7(4)$ \\
C-reactive protein (mg/L)* & $37(76.5)$ \\
Neutrophil-lymphocyte ratio* & $4.6(6.3)$ \\
Neutrophil-lymphocyte ratio, $\mathrm{n}(\%)$ & \\
$\quad 1$ & 20 \\
2 & 53 \\
3 & 112 \\
\hline
\end{tabular}

*Mean \pm standard deviation. NLR: Neutrophil-lymphocyte ratio.

/ ALT values were found to be high in 48 patients. All patients had right upper quadrant pain and tenderness during the physical examination. In 16 (8.6\%) patients, bilirubin values were found to be high. All patients underwent USG. MRI was performed on $16(8.6 \%)$ patients because of the suspicion of stones in the biliary tract. ERCP was performed on the bile ducts in 16 patients due to stones observed in the biliary duct. The mean NLR was found to be 4.6 6 6.3. The mean leukocyte value was $11.6 \pm 3.610^{9} / \mathrm{L}$ and the corresponding mean CRP value was $37 \pm 76.4 \mathrm{mg} / \mathrm{L}$, Overall, $90(48.6 \%)$ patients had a normal leukocyte count and $59(31.8 \%)$ patients had normal CRP values. In $20(10.9 \%)$ patients with NLR ratio of about 1, only 1 of these patients was aged $>60$ years and all the remaining patients were $<45$ years of age. The NLR value was found to be around 2 in 53 (28.6\%) patients and around $\geq 3$ in 112 $(60.5 \%)$ patients (Table 1$)$.

In $95(51.3 \%)$ patients, the leukocyte value was found to be high; 2 (1.1\%) of these patients had an NLR value of 1 , and the other $93(50.2 \%)$ patients had an NLR value of at least 2. CRP was found to be elevated in $91(49.1 \%)$ patients with a high leukocyte level and CRP was observed to be normal in $4(2.1 \%)$ patients. In all patients with an elevated leukocyte value, the NLR was determined to be at least 2 (Table 2).

In $49(26.4 \%)$ patients, the leukocyte and CRP values were normal and NLR was found to be at least 2. In 33 (17.8\%) patients, the leukocyte values were normal, but the CRP value was observed to be high and the NLR was at least 2. In $6(3.2 \%)$ patients, NLR, leukocyte and CRP values were found to be normal. In $2(1.1 \%)$ patients, only the CRP value was found to be high. Of the patients with nor- 
Table 2. laboratory test results of patients operated on for acute cholecystitis

\section{Total: 185}

\begin{tabular}{lccc}
\cline { 2 - 3 } Neutrophil-lymphocyte ratio & $\mathbf{1}$ & $\mathbf{2}$ & Total \\
\hline Leukocyte + C-reactive protein normal, $\mathrm{n}(\%)$ & $6(3.2)$ & $49(26.4)$ & $55(29.6)$ \\
Leukocyte N, C-reactive protein high, $\mathrm{n}(\%)$ & $2(1.1)$ & $33(17.8)$ & $35(18.9)$ \\
Leukocyte high, $\mathrm{n}(\%)$ & $2(1.1)$ & $93(50.2)$ & \\
Leukocyte high, C-reactive protein normal, $\mathrm{n}(\%)$ & 0 & $4(2.2)$ &
\end{tabular}

mal leukocyte and CRP values, 31 (63.2\%) were found to be over 50 years old. Of the $6(3.2 \%)$ patients with normal leukocyte, CRP and NLR values, 5 (83.3\%) were aged $>50$ years. In patients with normal leukocyte values and high CRP values and at least a 2-fold increase in NLR, 19 (57.5\%) were aged $\geq 50$ years.

Laparoscopic cholecystectomy was performed in all of the patients after being admitted to the emergency clinic and emergency surgery was performed on $1(0.54 \%)$ of the patients. In one patient, laparoscopic surgery was converted to open surgery. This patient was 84 years old, with the presence of pericholecystic fluid on USG, and during the operation an exposure problem developed because of an advanced degree of intra-abdominal adhesions, so it was decided to convert to open surgery. Mortality did not develop in any patient.

\section{Discussion}

It has been reported that approximately $5-10 \%$ of patients admitted with abdominal pain to Emergency Departments are diagnosed with acute cholecystitis. ${ }^{[4,5]}$ The Tokyo criteria are generally used for the diagnosis of acute cholecystitis. ${ }^{[3]}$ In the current study, the average age of patients was 51 years (50.2\%) and $55.1 \%$ of cases were female. Overall, $90(48.6 \%)$ patients had normal leukocyte values and 59 $(31.8 \%)$ patients had normal CRP values. In 20 (10.9\%) patients, the NLR was approximately, ${ }^{[1]}$ in $53(28.6 \%)$ patients the NLR was found to be approximately 2 times higher and in $112(60.5 \%)$ patients the NLR was increased 3-fold or more. The aim of this study was to determine whether the NLR could be of benefit in the diagnosis and treatment of acute cholecystitis.

Ultrasonography is preferred in the first diagnosis of patients with acute cholecystitis, with reported sensitivity and specificity rates of $95-99 \% .{ }^{[6]}$ MRI may be performed in patients with biliary stones or in cases of acute pancreatitis. ${ }^{[7,8]}$ USG was applied first to all of the patients in the current study, but 16 (8.6\%) patients also underwent MRI on suspicion of stones in the biliary tract and then ERCP was performed.

In patients with acute cholecystitis, the reasons for conversion from laparoscopy can be stated as age $>60$ years, male gender and the presence of pericholecystic fluid. ${ }^{[9]}$ The mortality rate from acute cholecystitis has been reported as approximately $1 \%,{ }^{[10]}$ although increased mortality and morbidity rates are observed in elderly patients. ${ }^{[11,12]}$ The morbidity rate after laparoscopy in acute cholecystitis varies between $3-30 \%{ }^{[13,14]}$ and some studies in literature have indicated that the rate of open surgery is higher than in cases of elective cholecystectomy. ${ }^{[15,16]}$ When the age of patients with acute cholecystitis is examined, the rate of cholecystitis can be seen to increase after the age of 50 years. ${ }^{[17]}$ Comorbid factors are very common in elderly patients and symptoms may be atypical with rapid disease progression in these patients. ${ }^{[17]}$ Mortality and morbidity rates are known to be significantly increased in cases of gangrenous cholecystitis, abscess and perforation, although the CRP and leukocyte values may not increase in some patients, especially the elderly. Therefore, early diagnosis and treatment may be vital in these patients. ${ }^{[18]}$ In the current study, no mortality developed and all the patients were operated on after referral for emergency surgery. Only $1(0.54 \%)$ patient underwent open surgery. This patient was 84 years old, with the presence of pericholecystic fluid on USG, and during the operation an exposure problem developed because of an advanced degree of intra-abdominal adhesions, so it was decided to convert to open surgery. Age $>50$ years was determined in $52.4 \%$ of the current study patients, and of these, 31 (63.2\%) had normal leukocyte and CRP values.

Acute cholecystitis is defined as an inflammation of the gallbladder, and most patients have gallstones, with rapid disease progression in $20 \%$ of these ${ }^{[19]}$ Many studies have stated that inflammation is a prognostic factor for various 
diseases. ${ }^{[20-22]}$ NLR is a biomarker for systemic inflammation, and the inflammatory response is characterized by neutrophilia and lymphopenia. ${ }^{[4]}$ At the same time, diseases characterized by acute inflammation of NLR can also be considered as a determining factor for the diagnosis and treatment of inflammation. High NLR values have been found to be related to a long hospital stay for patients with gangrenous appendicitis. ${ }^{[22,23]}$ Lee et al. ${ }^{[24]}$ found that the increase in NLR was higher in acute cholecystitis than in chronic cholecystitis and there was a higher risk of mortality in patients with NLR >3. In the current study, 90 (48.6\%) patients had normal leukocyte values and 59 (31.8\%) patients had normal CRP values. In $20(10.9 \%)$ patients, the NLR was found to be around 1. In 165 (89.1\%) patients, the NLR was found to be $\geq 2$, and of these, 49 (26.4\%) patients with normal leukocyte and CRP values had NLR $>2$.

It has been reported that $90-95 \%$ of patients examined for cholecystitis have acute cholecystitis and $5-10 \%$ are diagnosed with acalculous cholecystitis. ${ }^{[10]}$ In the current study, $98.4 \%$ of the patients examined were diagnosed with acute cholecystitis and all of the operated patients were operated on with the diagnosis of acute cholecystitis. The patient group in the current study comprised $55.4 \%$ females and the mean age was 51.5 years; these results were consistent with the literature. ${ }^{[25]}$

Limitations of this study can be said to be the retrospective nature of the study and that no evaluation was made according to the postoperative pathological data Furthermore, classification was not made according to the Tokyo criteria and so comparisons could not be made according to those criteria.

In conclusion, from the results obtained in this study, it can be considered useful to direct the treatment of patients diagnosed with acute cholecystitis from evaluations of NLR, CRP and leukocyte values together with physical examination and ultrasonography.

\section{Disclosures}

Ethichs Committee Approval: The study was approved by the Local Ethics Committee.

Peer-review: Externally peer-reviewed.

Conflict of Interest: None declared.

\section{References}

1. Peery AF, Crockett SD, Barritt AS, Dellon ES, Eluri S, Gangarosa LM, et al. Burden of Gastrointestinal, Liver, and Pan- creatic Diseases in the United States. Gastroenterology 2015;149:1731-41.e3. [CrossRef]

2. Fagenholz PJ, Fuentes E, Kaafarani H, Cropano C, King D, de Moya $\mathrm{M}$, et al. Computed Tomography Is More Sensitive than Ultrasound for the Diagnosis of Acute Cholecystitis. Surg Infect (Larchmt) 2015;16:509-12. [CrossRef]

3. Yokoe M, Takada T, Strasberg SM, Solomkin JS, Mayumi T, Gomi H, et al; Tokyo Guidelines Revision Committee. TG13 diagnostic criteria and severity grading of acute cholecystitis (with videos). J Hepatobiliary Pancreat Sci 2013;20:35-46.

4. Zahorec R. Ratio of neutrophil to lymphocyte counts-rapid and simple parameter of systemic inflammation and stress in critically ill. [Article in English, Slovak]. Bratisl Lek Listy 2001;102:5-14.

5. Durukan P, Çevik Y, Yıldız M. Valuableness of Scoring Systems In Evaluation of Critical Patient In Emergency Department For Geriatric Patients Turkish Journal of Geriatrics 2005;8:111-4.

6. Yeniocak $\mathrm{S}$, Turkmen $\mathrm{S}$, Uzun $\mathrm{O}$, et al. Akut karın ağrısıyla acil servise başvuran hastaların analizi. JAEM 2012;11:212-5.

7. Wilson AK, Kozol RA, Salwen WA, Manov LJ, Tennenberg SD. Gangrenous cholecystitis in an urban VA hospital. J Surg Res 1994;56:402-4. [CrossRef]

8. Virzì V, Ognibene NMG, Sciortino AS, Culmone G, Virzì G. Routine MRCP in the management of patients with gallbladder stones awaiting cholecystectomy: a single-centre experience. Insights Imaging 2018;9:653-9. [CrossRef]

9. Kim MS, Kwon HJ, Park HW, Park JY, Chung EC, Park HJ, et al. Preoperative prediction model for conversion of laparoscopic to open cholecystectomy in patient with acute cholecystitis: based on clinical, laboratory, and CT parameters. J Comput Assist Tomogr 2014;38:727-32. [CrossRef]

10. Kimura Y, Takada T, Strasberg SM, Pitt HA, Gouma DJ, Garden OJ, et al. TG13 current terminology, etiology, and epidemiology of acute cholangitis and cholecystitis. J Hepatobiliary Pancreat Sci 2013;20:8-23. [CrossRef]

11. Papadakis $M$, Ambe $P C$, Zirngibl H. Critically ill patients with acute cholecystitis are at increased risk for extensive gallbladder inflammation. World J Emerg Surg 2015;10:59. [CrossRef]

12. Haltmeier T, Benjamin E, Inaba K, Lam L, Demetriades D. Early versus delayed same-admission laparoscopic cholecystectomy for acute cholecystitis in elderly patients with comorbidities. J Trauma Acute Care Surg 2015;78:801-7. [CrossRef]

13. Kum CK, Goh PM, Isaac JR, Tekant Y, Ngoi SS. Laparoscopic cholecystectomy for acute cholecystitis. Br J Surg 1994;81:1651-4. [CrossRef]

14. Prakash K, Jacob G, Lekha V, Venugopal A, Venugopal B, Ramesh H. Laparoscopic cholecystectomy in acute cholecystitis. Surg Endosc 2002;16:180-3. [CrossRef]

15. Ambe PC, Weber SA, Christ $H$, Wassenberg D. Primary cholecystectomy is feasible in elderly patients with acute cholecystitis. Aging Clin Exp Res 2015;27:921-6. [CrossRef]

16. Fuks D, Duhaut $P$, Mauvais $F$, Pocard $M$, Haccart V, Paquet $\mathrm{JC}$, et al. A retrospective comparison of older and younger adults undergoing early laparoscopic cholecystectomy for 
mild to moderate calculous cholecystitis. J Am Geriatr Soc 2015;63:1010-6. [CrossRef]

17. Telfer S, Fenyö G, Holt PR, de Dombal FT. Acute abdominal pain in patients over 50 years of age. Scand $\mathrm{J}$ Gastroenterol Suppl 1988;144:47-50.

18. Prousalidis J, Fahadidis E, Apostolidis S, Katsohis C, Aletras H. Acute cholecystitis in aged patients. HPB Surg 1996;9:129-31. [CrossRef]

19. Parker LJ, Vukov LF, Wollan PC. Emergency department evaluation of geriatric patients with acute cholecystitis. Acad Emerg Med 1997;4:51-5. [CrossRef]

20. Roxburgh CS, McMillan DC. Role of systemic inflammatory response in predicting survival in patients with primary operable cancer. Future Oncol 2010;6:149-63. [CrossRef]

21. Zhang L, Wang R, Chen W, Xu X, Dong S, Fan H, et al. Prognostic significance of neutrophil to lymphocyte ratio in patients with gallbladder carcinoma. HPB (Oxford) 2016;18:600-7.

22. Ranzani OT, Zampieri FG, Forte DN, Azevedo LC, Park M. Creactive protein/albumin ratio predicts 90 -day mortality of septic patients. PLoS One 2013;8:e59321. [CrossRef]

23. Kim MH, Ahn JY, Song JE, Choi H, Ann HW, Kim JK, et al. The C-Reactive Protein/Albumin Ratio as an Independent Predictor of Mortality in Patients with Severe Sepsis or Septic Shock Treated with Early Goal-Directed Therapy. PLoS One 2015;10:e0132109. [CrossRef]

24. Lee SK, Lee SC, Park JW, Kim SJ. The utility of the preoperative neutrophil-to- lymphocyte ratio in predicting severe cholecystitis: a retrospective cohort study. BMC Surgery. Available at: https://bmcsurg.biomedcentral.com/articles/10.1186/1471-2482-14-100. Accessed June 21, 2019.

25. Halpin V, Gupta A. Acute cholecystitis. BMJ Clin Evid. $2011 ; 2011$. 